\title{
THICKNESS AND STRUCTURE OF ANTARCTIC SEA ICE MEASURED BY DRILLING AND IMPULSE RADAR
}

by

\section{Hirokazu OHMae}

Institute of Low Temperature Science, Hokkaido University, Sapporo, Japan 060

FUмIнIKо NisHIO

National Institute of Polar Research, 9-10, Kaga 1-chome, Itabashi-ku, Tokyo, Japan 173

\section{ABSTRACT}

Sea ice thickness was profiled in investigating the internal structure of sea ice in August 1982 near Syowa Station, East Antarctica, by drilling and using an impulse radar system. In this connection, the anisotropic properties of sea ice were studied by rotating the radar antenna on the horizontal surface of ice around the vertical axis. Ice cores $155 \mathrm{~cm}$ long were drilled for analysis of their internal structure, which showed that a brine-soaked layer existed at the depth of $90 \mathrm{~cm}$. This layer corresponded to an internal echo of very strong intensity at this depth that did not change during the rotation of the antenna. Meanwhile, a bottom echo gave maxima and minima approximately every 90 degrees of rotation of the antenna; this alternation is attributable to the structure of newly grown ice with the preferred c-axis orientation. From these findings we consider that two types of sea ice covered the area near Syowa Station: one with a brine-soaked layer; the other without. Irregularities in shape of the bottom echo suggest that the sea ice plane was composed of accumulated small plates of sea ice.

\section{INTRODUCTION}

Physical and electromagnetic properties of sea ice were characterized by data analyzed from cores drilled at several points on the surface of a firn layer on an ice shelf (Kovacs and Morey 1979, Kovacs and Gow 1975). The thickness of the sea ice was profiled by direct measurements of the drilled cores, and also by a remote sensing technique using an impulse radar system which conducted continuous sounding onto this surface from which profiling was possible.

Electromagnetic properties of sea ice, which vary considerably, are reflected on radar echoes during soundings. This makes it possible to divide sea ice into several types as well as disclosing its anisotropic structure. Interpretation of internal and bottom echoes was supported by our analysis of the drilled sea ice cores.

\section{EXPERIMENT}

An experiment was carried out using an impulse radar system on sea ice in an area (Figure 1) near Syowa Station $\left(69^{\circ} 00^{\prime} \mathrm{E}, 39^{\circ} 35^{\prime} \mathrm{S}\right)$, East Antarctica, in August 1982. The continuous thickness of sea ice was profiled over a distance of about $3 \mathrm{~km}$ from station 1 to station 5 . Two impulse radars transmitted a wavelet, one about 2 -ns duration and the other about 3-ns duration; wavelet frequencies were centered respectively at about 300 and $500 \mathrm{MHz}$. polarized dipole antenna was used for transmission and reception. The radar reflection wave were modulated and recorded on a graphic recorder.

A short impulse of electromagnetic energy transmitted from the antenna was reflected from one or more subsurface layers back to the antenna. These reflections provided information on the structure of sea ice: the number of layers detected and the strength of bottom and

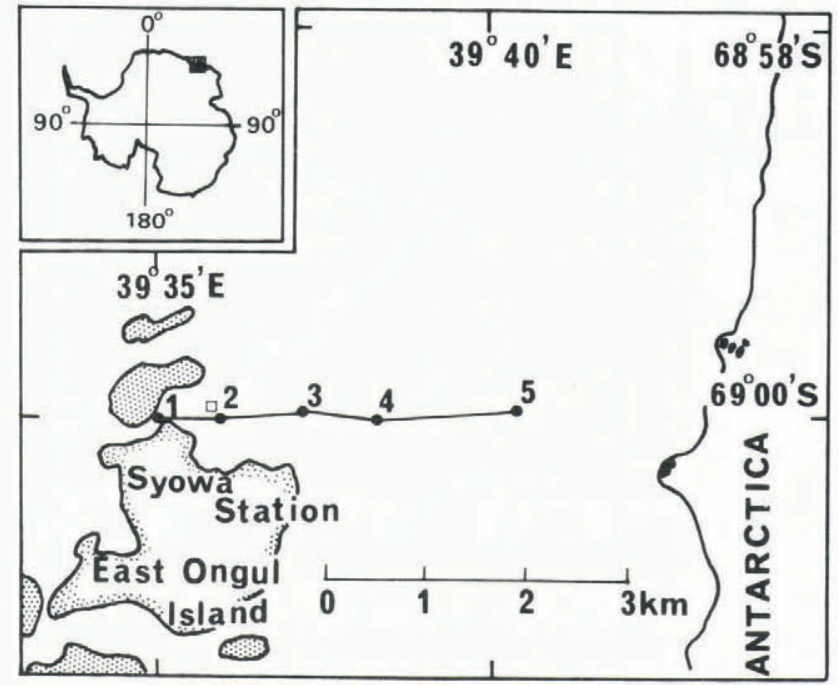

Fig.1. Map of investigated area. The solid line is the transection for thickness profiling.

internal echoes depended on the electrical characteristics (such as dielectric constant or conductivity) of the layers.

Thickness of sea ice was profiled over a distance of about $3 \mathrm{~km}$ by towing the antenna from an oversnow vehicle equipped with recording apparatus. As the surface of sea ice on the survey line was partly covered with snow, the time-lag due to the snow layer was not corrected.

In investigating the relation between the anisotropic structure of sea ice and reflected signals, the amplitude of the bottom signal may depend markedly on the azimuthal orientation of the polarized antenna of the impulse radar system. The procedure of the experiment specified that the antenna was positioned horizontally parallel to the ice surface and rotated around the vertical axis. To investigate the structure of sea ice, an ice core $155 \mathrm{~cm}$ in length was drilled at station 2 and cut into about $3 \mathrm{~cm}$ long sections; after each section's density had been measured, they were bagged up for later determination of conductivity of meltwater. Meltwater salinity was obtained by comparison with standard sea water, and the brine volume of sea ice was calculated from the temperature and salinity at each depth as follows:

$$
\mathrm{V}_{\mathrm{b}}=\mathrm{S}(49.185 / \mathrm{T}+0.532) \times 10^{-3},-0.5^{\circ} \mathrm{C}<\mathrm{T}<-22.9^{\circ} \mathrm{C}
$$

where $\mathrm{S}$ is the salinity $(\% \circ)$ and $\mathrm{T}$ is the absolute value of ice temperature in ${ }^{\circ} \mathrm{C}$ (Golden and Ackley 1981). 


\section{RESULTS AND DISCUSSION}

An ice core was drilled at station 2 down to the depth of $155 \mathrm{~cm}$. The structure of sea ice crystals was studied visually. From the result of core analyses, we obtained the distribution of density, salinity and brine volume (Figure 2). This shows a clear boundary at the depth of $90 \mathrm{~cm}$. The sea ice above this was composed of fine-grained ice crystals with random c-axis orientation and

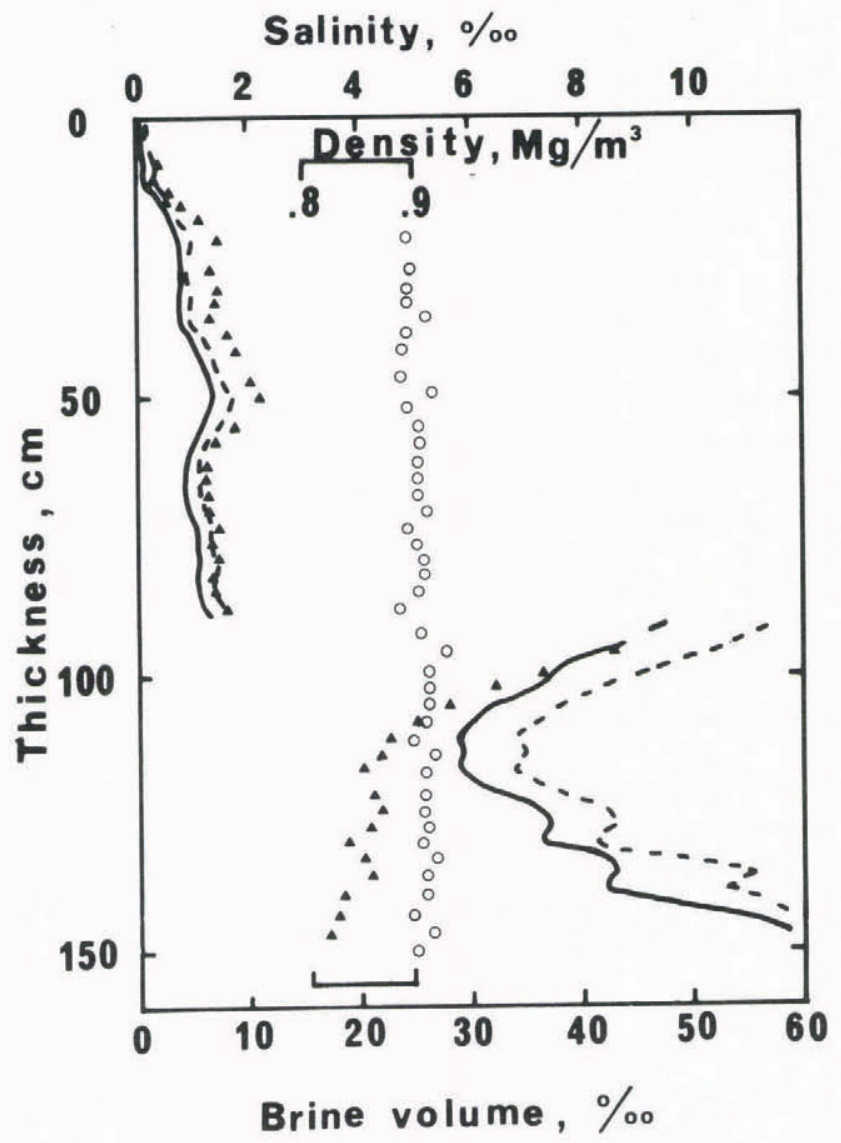

Fig.2. Distribution of density (O), salinity $(\Delta)$ and brine volume obtained by core analyses. The solid line shows the distribution of brine volume calculated from an assumed linear temperature distribution using daily mean air temperature and sea water temperature. The broken line shows the distribution of brine volume based on an assumed temperature distribution using daily maximum air temperature and sea water temperature.

with large air bubbles; the ice below was composed of long, columnar ice crystals. Brine volume was calculated from two temperature distributions, assuming that the upper surface temperature was that of air, the bottom temperature was that of sea water, and the temperature within the sea ice linearly changed between the two. The calculation was made for two surface temperatures, daily-mean air temperature and daily-maximum air temperatures. Differences in distribution were less than $15 \%$, and the shapes of the two temperature distributions had the same pattern. Distributions of salinity and brine volume show drastic change at $90 \mathrm{~cm}$ depth, and the patterns of their distributions below this indicate first year ice. A small change in density distribution was found at this depth which may result from a sharp change in brine volume. These findings suggested strongly that sea ice between stations 1 and 4 was multiyear ice.

Figure 3 shows a graphic record along the surveyed line from station 1 to station 5 . There are several strong internal and bottom echoes, and also false echoes caused by multiple reflection. The structure of this ice will be clarified by data obtained in analysis of the drilled ice core. Remarkable internal layers, which reflected strong signals, exist over more than $2 / 3$ of the surveyed line from station

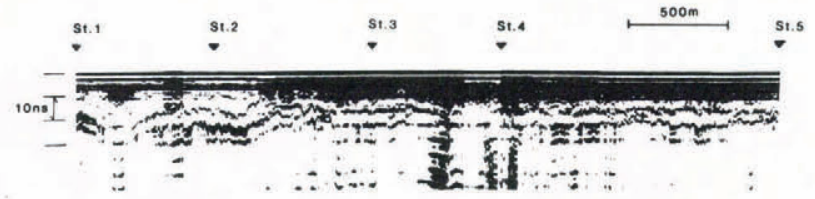

Fig.3. A graphic record obtained between station 1 and station 5 . Operating frequency: $300 \mathrm{MHz}$.

1 to station 4. No strong internal echoes, but many weak internal echoes, are found along the surveyed line between station 4 and station 5 . We consider from these data that two types of sea ice exist along the surveyed line.

The intensity of bottom echoes changed markedly at some places; in other places indicated by the broken line (Figure 3) no bottom echo was found. Its absence is related to the anisotropic structure of the bottom layer. Profilings of bottom echoes show corrugations, possibly formed by the large number of small plates which make up the sea ice plane.

Investigating the anisotropic property of sea ice by rotating the antenna around the vertical axis, the intensity of the bottom echoes showed maxima and minima at approximately $90^{\circ}$ intervals, but internal echoes with strong intensity were constant. Maximum bottom echoes are considered to occur when the direction of the electric field of radio waves is parallel with the preferred c-axis orientation of sea ice, and minimum bottom echoes occur when this direction is perpendicular to it. Crystal growth takes place at the sea ice/sea water interface and newly grown ice has a platelet structure with uniform c-axis orientation. Thus, alternating of intensity of the bottom echo is caused by changes in the preferred c-axis orientation, due to a mosaic of plates with slightly differing orientations. Thus the sheet of sea ice which looks like one plate is composed of many small plates, each with a different orientation of platelet structure at the bottom.

From these results we conclude that the remarkable internal layer with strong echoes, where the intensity of echoes does not change during the rotation of the antenna, corresponds to the boundary at the $90 \mathrm{~cm}$ depth where an abrupt change takes place in distributions of salinity and brine volume. If this is correct, average dielectric constant of sea ice from the surface to the bottom becomes 5.9, which is calculated from the time duration of wavelets between transmission and reception. This value compares reasonably with the general value of between 3 and 6 obtained by Golden and Ackley (1981).

There was no noticeable internal echo along about $1 / 4$ of the surveyed line from station 4 to station 5 . This suggests that no brine layering existed within the ice in this area. The intensity of bottom echoes too was weaker in this area. Absence of internal echoes might have been due to this ice being newly grown throughout its thickness, and the weaker intensity of bottom echoes due to electromagnetic energy being almost completely reflected on the surface, unable to penetrate into the sea ice through a high salinity surface texture. Alternately, internal structure may have been complicated because of gathered deformed old ice crystals. Because the sea did not become open water in the austral summer of 1982 around Syowa Station, the second explanation seems to apply particularly to the sea ice between stations 4 and 5 .

\section{CONCLUSION}

Figure 4 shows schematic results which summarize the profilings and the structure of the sea ice investigated using an impulse radar system. Profiling showed that the sea ice plane near Syowa Station was composed of small sea ice plates: profiling helped by ice core analysis revealed that sea ice between station 1 and station 4 had a different character from that between station 4 and station 5 . The two types of sea ice were defined as "type a" and "type b" respectively. The former was typical multiyear ice with a brine-soaked layer; the latter had no brine-soaked layer, being composed of gathered old ice crystals. Thus the impulse radar system provided information on variations 


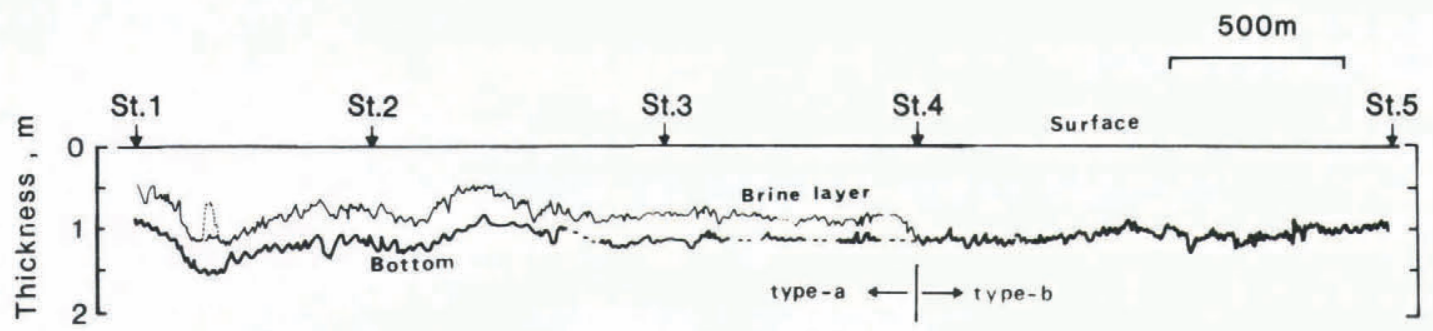

Fig.4. Schematic profile of sea ice thickness and profile of the brine-soaked layer along the surveyed line. The explanation of "type a" and "type b" is in the text.

within the sea ice covering the area, and of sea ice age, with help of a few ice core analyses; it also revealed the continuous internal structure of sea ice with a brine-soaked layer and the preferred c-axis orientations of newly-grown ice at the bottom.

\section{REFERENCES}

Golden K M, Ackley S F 1981 Modeling of anisotropic electromagnetic reflection from sea ice. Journal of Geophysical Research 86(C9): 8107-8116

Kovacs A, Gow A J 1975 Brine infiltration in the McMurdo Ice Shelf, McMurdo Sound, Antarctica. Journal of Geophysical Research 80(15): 1957-1961

Kovacs A, Morey R M 1979 Anisotropic property of sea ice in the $50-$ to $150-\mathrm{MHz}$ range. Journal of Geophysical Research 84(C9): 5749-5759 